\title{
Bacterial Composition, Community Structure, and Diversity in Apis nigrocincta Gut
}

\author{
Christian Apolinaris Lombogia, ${ }^{1,2}$ Max Tulung, ${ }^{1}$ Jimmy Posangi, ${ }^{1,3}$ \\ and Trina Ekawati Tallei $\mathbb{i D}^{4}$ \\ ${ }^{1}$ Entomology Study Program, Postgraduate Program, Sam Ratulangi University, Manado, North Sulawesi, Indonesia \\ ${ }^{2}$ Nursing Study Program, Faculty of Nursing, De La Salle Catholic University, Manado, North Sulawesi, Indonesia \\ ${ }^{3}$ Public Health Study Program, Faculty of Public Health, Sam Ratulangi University, Manado, North Sulawesi, Indonesia \\ ${ }^{4}$ Department of Biology, Faculty of Mathematics and Natural Sciences, Sam Ratulangi University, Manado, \\ North Sulawesi, Indonesia \\ Correspondence should be addressed to Trina Ekawati Tallei; trina_tallei@unsrat.ac.id
}

Received 25 December 2019; Accepted 8 July 2020; Published 30 July 2020

Academic Editor: Clemencia Chaves-López

Copyright (c) 2020 Christian Apolinaris Lombogia et al. This is an open access article distributed under the Creative Commons Attribution License, which permits unrestricted use, distribution, and reproduction in any medium, provided the original work is properly cited.

\begin{abstract}
Understanding the honeybee gut bacteria is an essential aspect as honeybees are the primary pollinators of many crops. In this study, the honeybee-associated gut bacteria were investigated by targeting the V3-V4 region of 16S rRNA genes using the Illumina MiSeq. The adult worker was captured in an urban area in a dense settlement. In total, 83,018 reads were obtained, revealing six phyla from 749 bacterial operational taxonomic units (OTUs). The gut was dominated by Proteobacteria (58\% of the total reads, including Enterobacteriaceae 28.2\%, Erwinia 6.43\%, and Klebsiella 4.90\%), Firmicutes (29\% of the total reads, including Lactococcus garvieae 13.45\%, Lactobacillus spp. $8.19 \%$, and Enterococcus spp. $4.47 \%$ ), and Actinobacteria (8\% of the total reads, including Bifidobacterium spp. 7.96\%). Many of these bacteria belong to the group of lactic acid bacteria (LAB), which was claimed to be composed of beneficial bacteria involved in maintaining a healthy host. The honeybee was identified as Apis nigrocincta based on an identity BLAST search of its COI region. This study is the first report on the gut microbial community structure and composition of $A$. nigrocincta from Indonesia.
\end{abstract}

\section{Introduction}

Honeybees, members of the genus Apis, are social insects, that are famous for their honey production. Nine species of honeybees are currently known to inhabit the world: Apis dorsata, A. laboriosa, A. mellifera, A. florea, A. andreniformis, A. cerana, A. koschevnikovi, A. nigrocincta, and A. nuluensis. Honeybees play indispensable roles in pollination. However, their population tends to decline in recent years [1]. This decline will cause severe problems in pollination services in both agricultural and natural settings, thus threatening the world's food supply.

Honeybees have become essential models in studying the influence of microbial communities with their hosts [2]. Various factors, among others, govern the complex microbiome community in the gut of the insects, is the flowers they visit. The insect hosts provide an environment that supports microbial growth in the gut, which benefits the hosts [3], such as synthesizing and absorbing nutrients. Several studies reveal that their microbial community may be involved in pathogen defense [4] and play significant roles in the growth, development, and environmental adaptation of the host, as well as bioprospecting [5].

It is estimated that there are approximately one billion bacterial cells in an adult workers with diverse types of bacteria $[6,7]$. Such diversity will ensure a healthy gut to resist pathogens. The composition of this microbiota is associated with the environment [8]. However, the core bacterial community is relatively constant across populations and geographical areas [9]. The gut community of 
worker honeybees is dominated by nine bacterial species clusters [10], with five core bacterial species resident mainly in hindguts [11]. The current study is aimed to characterize the gut microbial community structure of wild honeybee found in an urban area with dense settlements.

\section{Material and Methods}

2.1. Sample Preparation. The honeybee was captured in March 2019 from an abandoned garden in Mahakeret, Manado, North Sulawesi, Indonesia. The location is in an urban area with dense settlements. The honeybee was surface-sterilized by immersing it in $1.0 \%$ sodium hypochlorite for $10 \mathrm{~min}$. Then, it is transferred into $70 \%$ ethanol for $2 \mathrm{~min}$, and rinsed with sterile distilled water three times. The insect was dried using a sterile tissue paper.

2.2. Identification of the Honeybee. Mitochondrial DNA (mtDNA) was extracted from the base of the coxa, which is connected to the abdomen, according to Tallei et al. [12]. The mtDNA was prepared using The ZR Tissue and Insect DNA MiniPrep $^{\text {TM }}$ (Zymo Research) by following the instruction provided by the manufacturer. The extraction product was cleaned using The DNA Clean and Concentrator ${ }^{\mathrm{TM}}-5$ $\left(\mathrm{DCC}^{\mathrm{TM}}-5\right)$ to obtain high-quality DNA for PCR. The amplification of COI (cytochrome c oxidase subunit 1) region was performed using Toyobo KOD FX Neo PCR Master Mix using primer pairs LCO1490 and HCO2198. The sequences of the primers are LCO1490 5'GGTCAACAAATCATAAAGATATTGG3' and $\mathrm{HCO}^{\prime} 198$ 5' TAAACTTCAGGGTGACCAAAAAATCA3' [13]. The PCR condition was as follows: $2 \mathrm{~min}$ initial denaturation at $95^{\circ} \mathrm{C}$ followed by 35 cycles of denaturation at $98^{\circ} \mathrm{C}$ for $10 \mathrm{sec}$, annealing at $54^{\circ} \mathrm{C}$ for $30 \mathrm{sec}$, elongation at $68^{\circ} \mathrm{C}$ for $45 \mathrm{~min}$, and additional extension for $5 \mathrm{~min}$ at $68^{\circ} \mathrm{C}$. The amplicons were sequenced using the same primer pairs at 1st BASE DNA Sequencing Services Malaysia.

2.3. COI Data Analysis. The chromatograms were processed following the procedure performed by Tallei and Kolondam [14]. The clean COI sequence was deposited in GenBank (http://www.ncbi.nlm.nih.gov). Identification was performed using the BLAST identity search at the same platform.

2.4. Bacterial gDNA Extraction and Amplification. The honeybee's gut was dissected under sterile conditions and homogenized in a FastPrep-24 Instrument at $4 \mathrm{~m} / \mathrm{s}$ for $25 \mathrm{sec}$. The subsequent procedure was done according to Fatimawali et al. [15]. The extraction of gut bacterial gDNA (genomic DNA) was performed using ZymoBiomics DNA Mini Kit (Zymo Research) following the manufacturer's protocol. The gDNAs were evaluated by electrophoresis on a $0.8 \%$ agarose and analyzed using NanoDrop 1000 (Thermo Scientific, Wilmington, DE, USA). The hypervariable V3-V4 regions of $16 \mathrm{~S}$ rRNA gene were amplified using $\mathrm{MyTaq}^{\mathrm{TM}} \mathrm{HS}$ Red Mix (Bioline, BIO-25044) in Agilent SureCycler 8800
Thermal Cycler with the following reaction condition: initial denaturation at $95^{\circ} \mathrm{C}$ for $3 \mathrm{~min}$, followed by 35 cycles of denaturation at $95^{\circ} \mathrm{C}$ for $15 \mathrm{sec}$, annealing at $52^{\circ} \mathrm{C}$ for $30 \mathrm{sec}$, and extension at $72^{\circ} \mathrm{C}$ for $45 \mathrm{sec}$, and then followed by a final extension at $72^{\circ} \mathrm{C}$ for $3 \mathrm{~min}$.

2.5. 16S rRNA Library Preparation. The following procedure was done according to Tallei et al. [16]. An Illumina two-step PCR protocol was used for preparing the amplicons library. The first stage was to generate PCR products of V3-V4 regions using Nextera-style tag sequences (overhang sequences) with the following sequences: forward overhang P5-tag: 5'TCGTCGGCAGCGTCAGATGTGTAT AAGAGACAG-[locus-specific sequence] and reverse overhang P7tag: $\quad$ ' $\quad$ GTCTCGTGGGCTCGGAGATGTGTATAAGAGACAG-[locus-specific sequence]. The second stage used sample-specific Illumina Nextera XT dual indices (Nextera XT i7 index and Nextera XT i5 index) with the following sequences: P5-PCR index primer: 5'AATGATACGGCGACCACCGAGATCTACAC[i5]TCGTCGGCAGCGTC and P7-PCR index primer: 5'CAAGCAGAAGACGGCATACGAGAT[i7]GTCTCGTGGGC TCGG. The final products were assessed using TapeStation 4200 from Agilent Technologies, HelixyteTM green dsDNA quantifying reagent, and qPCR using Jetseq library quantification Lo-Rox kit from Bioline (London, $\mathrm{UK})$. The paired-end sequences were generated in a $2 \times 300 \mathrm{bp}$ format from MiSeq.

2.6. Bioinformatics Analysis. The following procedure was done according to Tallei et al. [16]. Removal of sequence adapters of the raw sequences was performed using Bbmap and merged using BBMerge (BBTools package). After alignment, trimming, and chimeras removal, all reads were clustered into OTU using UCLUST (de novo) using a $97 \%$ similarity threshold. Prior to taxonomy and diversity analysis, singleton and doubletons were removed. The samples were subsequently rarefied to the lowest number of reads among all samples.

2.7. Analysis of Honeybee Bacterial Diversity. The alpha diversity of the bacterial gut was calculated and analysed using PAST3 v. 3.24 [17]. The alpha diversity was represented by dominance $(D)$, Simpson $(1-\mathrm{D})$, Shannon-Wiener $\left(\mathrm{H}^{\prime}\right)$, evenness (eH/S), Margalef (Dmg), and equitability $(J)$ indices [15].

\section{Results and Discussion}

3.1. Identification of the Honeybee. The cytochrome oxidase I (COI) sequence of the honeybee captured at the Mahakeret area has been deposited in GenBank with accession number MK880239. Based on BLAST identification, the specimen shared $99.50 \%$ identity with Apis nigrocincta from Sangihe Island, North Sulawesi (GenBank Accession AP018398). Apis nigrocincta has been recorded to inhabit Mindanao island (the Philippines), Sangihe islands (North Sulawesi, 
Indonesia), and the main island of Sulawesi (Indonesia). This honeybee nests in cavities near the ground, such as holes in trunks and caves [18]. Like other honeybees, this species is a generalist and visits a broad range of plants for food.

3.2. Bacterial Microbiome Composition of A. nigrocincta Gut. A large number of reads of the bacterial microbiome was produced by Illumina sequencing from the gut of $A$. nigrocincta. After the removal of chimera and singleton, there were 83,018 reads of $16 \mathrm{~S}$ rRNA V3-V4 region sequence. In total, based on $16 \mathrm{~S}$ rRNA sequences, the microbiome in A. nigrocincta gut was identified as belonging to six phyla of bacteria (from most abundant to least: Proteobacteria, Firmicutes, Actinobacteria, Bacteroidetes, Cyanobacteria, and Planctomycetes) (Figure 1). Predominant phyla included 58\% Proteobacteria, 29\% Firmicutes, and $8 \%$ Actinobacteria. Some previous studies demonstraing that honeybee workers have a unique microbial community that is composed predominantly of three major bacterial phyla (Firmicutes, Proteobacteria, and Actinobacteria) $[10,18-22]$. Yun et al. [21] found that, on average, the insect gut bacterial microbiota was dominated by $62.1 \%$ Proteobacteria and 20.7\% Firmicutes. Approximately one billion bacterial cells reside in the gut of mature honeybee workers, and $\sim 95 \%$ are in the hindgut [8].

3.3. Diversity of the Bacterial Microbiome. The taxonomic composition of the microbiome at the bacterial class level was $\gamma$-Proteobacteria (48.9\%), Bacilli (28.8\%), and Actinobacteria $(8 \%)$ with a total of $85.7 \%$ (Figure 2). A similar finding was described by Lee et al. [23] and Horton et al. [19]. They found that the bacterial community of worker bee gut is dominated by $\gamma$-Proteobacteria, Bacilli, and Actinobacteria (total 90\%).

Six bacterial families were predominant: Enterobacteriaceae $(44.3 \%)$, Streptococcaceae (13.2\%), Lactobacillaceae (8.1\%), Bifidobacteriaceae (7.9\%), Neisseriaceae (6.3\%), and Enterococcaceae (5.8\%). The most abundant genera (Figure 3) were within Firmicutes (Lactococcus 13.5\%; Lactobacillus 8.2\%; Enterococcus 4.7\%), Actinobacteria (Bifidobacterium 8\%), and Proteobacteria (Erwinia 6.4\%; Klebsiella 4.9\%; Citrobacter 2.5\%) (Figure 3). Martinson et al. [6] reported that the core clades of adult worker bee included two species from Firmicutes, one species from Actinobacteria, and six species from Proteobacteria. Throughout their lifetime, bees perform different tasks, depending on their age. This might as well contribute to the microbiome community in their guts, especially as they visit different kind of hosts.

Enterococcus was accounted for $4.47 \%$ of the gut bacterial population in A. nigrocincta. This genus is coccishaped lactic acid bacteria (LAB) which commonly found as gut and honeycomb microflora and known to produce an antimicrobial compound. Enterococcus haemoperoxidus (found in small number, 79 reads) was probably ingested by the insect from flowers. Linjordet [24] reported that this species was found in rapeseed. It can also be assumed that

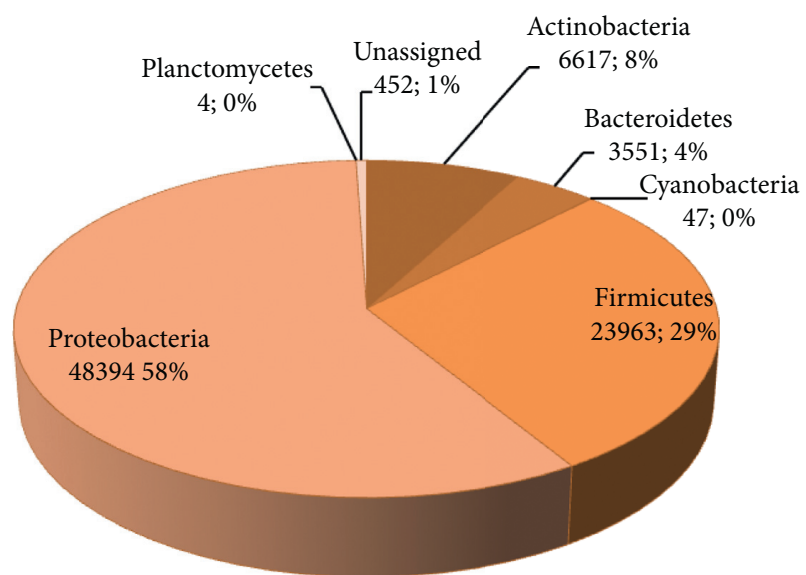

Figure 1: Six phyla of bacteria found in A. nigrocincta gut.

the insect acquired the species from water, as Svec et al. [25] reported that the bacteria were found in water. Yun et al. [26] reported that insect gut bacterial diversity was determined among others by its habitat and diet. However, the composition of the microbiome in A. mellifera workers is reasonably consistent. This suggests that genotypic variation does not affect the gut microbiome of the honeybee [27]. However, the previous study showed that strains in honeybees and bumblebees are host-specific, as they are only able to colonize their native hosts [28].

Lactococcus garvieae was found in quite a large number (11166 reads or 13.5\%). Linjordet [24] found this species in willowherb (a herbaceous flowering plant in the family Onagraceae), accounting for $30 \%$ of the bacterial population. This species is a fish pathogen associated with different human infections [29, 30]. However, Zhang et al. [31] reported that L. garviae B301 could be potentially used as animal-feed probiotic as it improved the health of broiler chicken and enhanced their performances. They even suggested that this strain could be potentially used as a feed additive for broiler chickens. Abdelfatah and Mahboub [32] reported that $L$. garviae originating from dairy products produced a bacteriocin-like inhibitory substance. This species is considered as LAB and has been used in manufacturing cheese and fermented milk products [33].

Morganella morganii was only found in a small number (18 reads). The species isolated from indigenous honeybees of Saudi Arabia caused mortality of Paenibacillus larvae spores by $86.67 \%$ [20]. Paenibacillus larvae is a deadly pathogen of honeybee larvae. Lamei et al. [34] reported that there were 13 species of $\mathrm{LAB}$ were found in the crop of $A$. mellifera within the genera Lactobacillus and Bifidobacterium. As much as 6609 reads (7.96\%) of Bifidobacterium and 6802 reads $(8.19 \%)$ of Lactobacillus were detected in A. nigrocincta gut. These LAB could play a vital role in honeybee health, protecting them against bee pathogens $[35,36]$, supporting food processing such as carbohydrate metabolism [7, 23], and contributing to the antimicrobial properties of honey [37].

As reported by Huang et al. [38], the dominant genera of gut microbiota of A. cerana, the closest taxa of A. nigrocincta, were Serratia, Snodgrassella, and Lactobacillus. Some lactic 


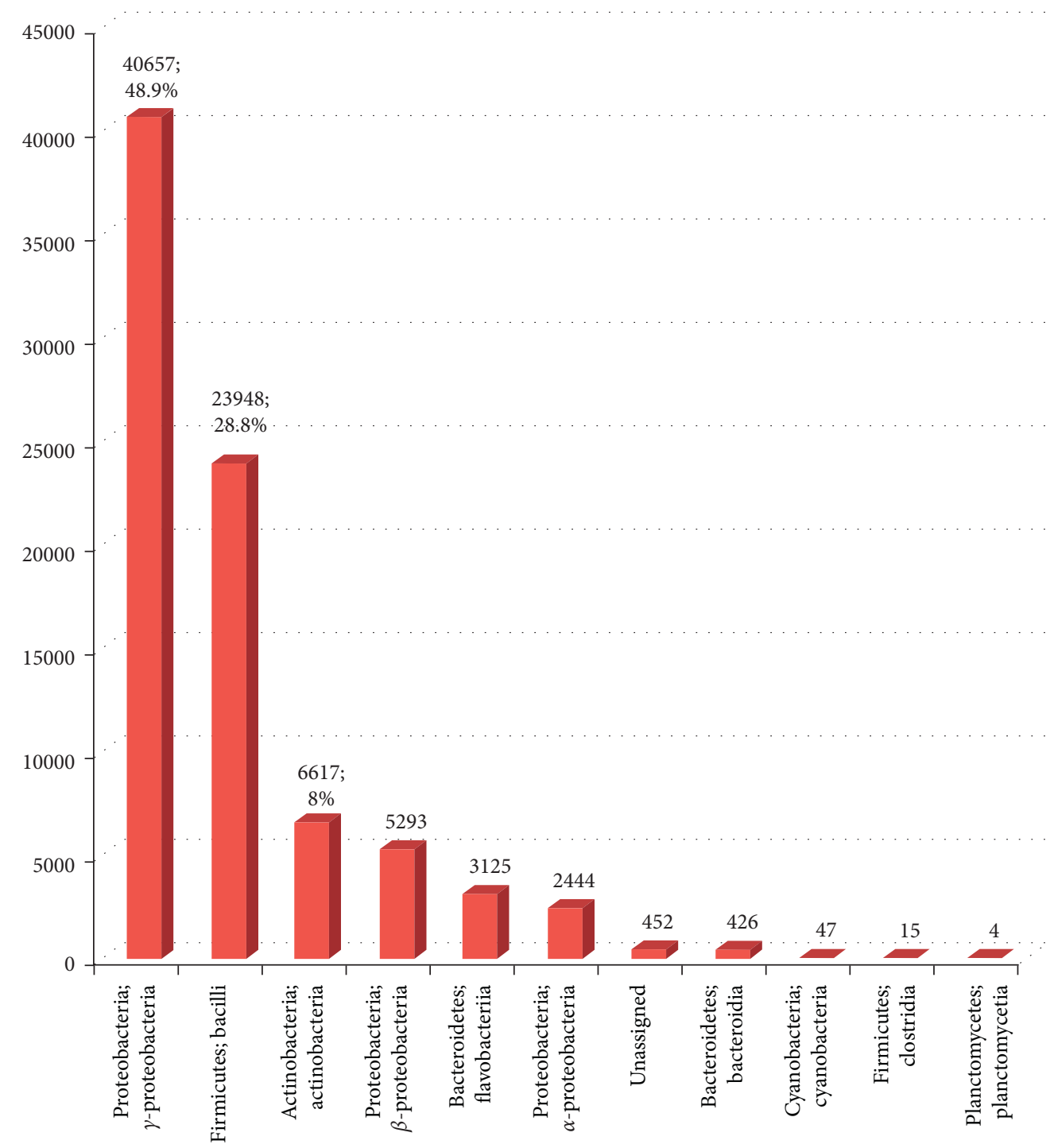

Figure 2: Relative frequency of bacterial class level in A. nigrocincta gut.

acid bacteria such as several Lactobacillus species produce several antimicrobial compounds including organic acids, hydrogen peroxide, bacteriocin, reuterin, and reutericyclin. These compounds inhibit decaying and pathogenic bacteria, both Gram positive and negative, and some fungi $[39,40]$. This indicates the probability that honeybees use gut bacteria as probiotics [28].

The abundance and diversity of probiotics in thehoneybee's gut are prerequisites for their health, considering that the gut is very susceptible to pathogenic and parasitic infections [34]. The gut microbial composition will show the health condition of the bees, since disruption of this composition has been associated with detrimental effects on their health [11]. Linjordet [24] reported that L. kunkeei and Fructobacillus fructosus were the most abundant in the honeybee gut. Fructobacillus (50 reads; $0.05 \%$ ) is a fructophilic LAB that prefers fructose instead of glucose as a growth substrate. The low abundance of Bifidobacteriaceae and Lactobacillaceae was speculated to be impacted by the appearance of pathogens in the gut [41].
Genera within Enterobacteriaceae (28.22\%) that were detected in $A$. nigrocincta gut, among others, were Citrobacter $(2.0 \%)$, Klebsiella (4.90\%), Providencia (0.85\%), Proteus (0.8\%), and Erwinia (6.43\%). Seemingly, these genera are commonly found in the alimentary tract of adult bees. Their presence was dependent on neither seasonal nor food factors [42]. Disayathanoowat et al. [43] stated that $K$. pneumoniae was the most abundant species of bacteria from the midgut of the Asian honeybee (Apis cerana indica).

Neisseriaceae (5273 reads; $6.35 \%$ ) was also found in $A$. nigrocincta gut. Liu et al. [44] found $N$. meningitidis in African honeybee (A. mellifera). Kwong and Moran [45] reported that this family is a gut symbiont of honeybees and bumblebees, accounting for approximately 30\% of the microbiota [9]. Members of the core gut of $A$. mellifera community include Snodgrassella alvi (Betaproteobacteria: Neisseriales, Gilliamella apicola, and Frischella perrara (Gammaproteobacteria: Orbales) [1].

Weeksellaceae (3.75\%; Bacteroidetes) was predominant in the larval and pupal stages of Bactrocera carambolae 


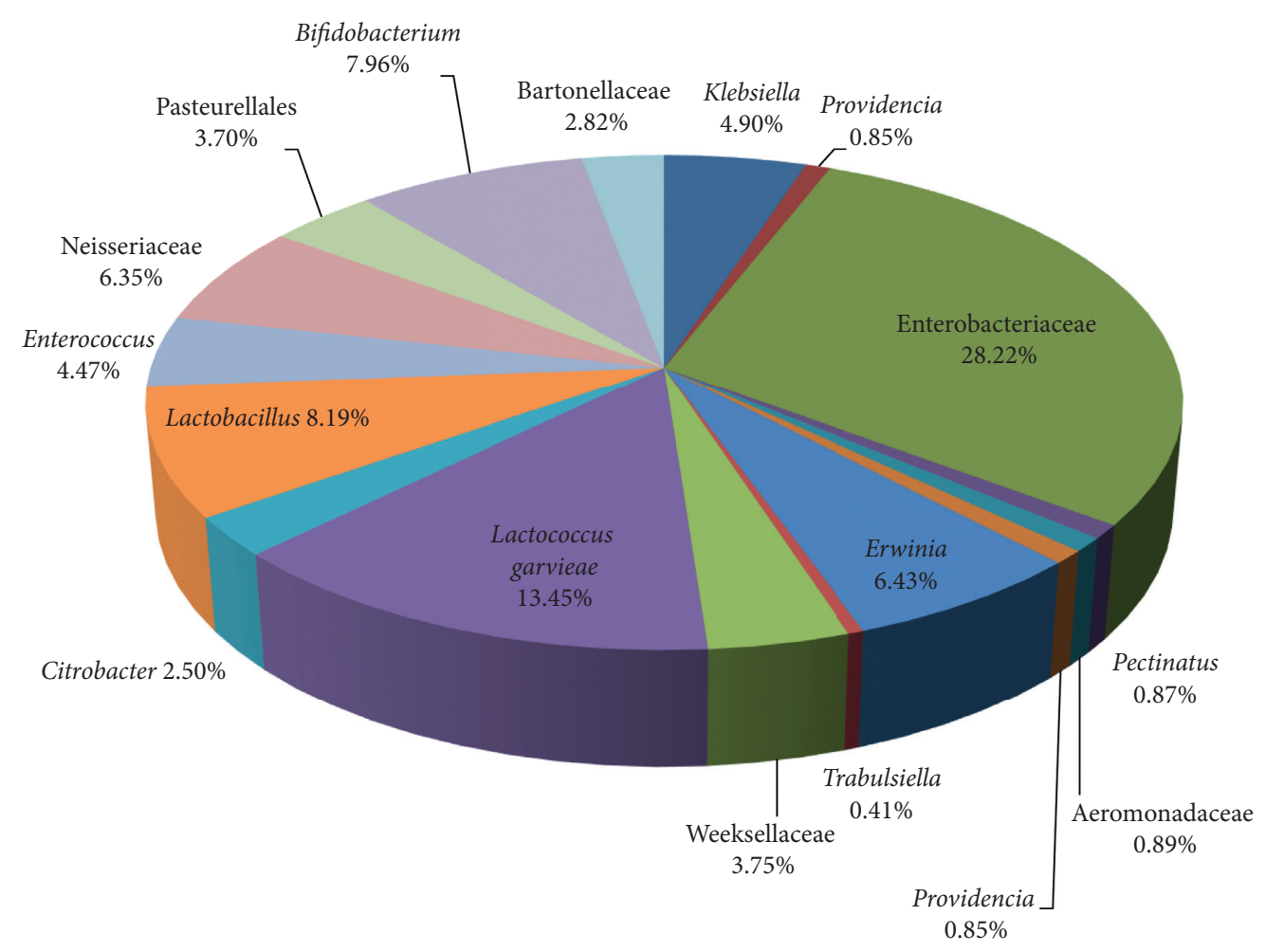

Figure 3: The most abundant genera (including some predominant families) in the gut of A. nigrocincta.

(Insecta: Tephritidae) [46]. Their population was higher in bees fed with bee-bread and was associated with Nosema ceranae infection in bees fed with sugar solution [38]. Bartonellaceae was found in a low number of reads $(2.82 \%)$ in A. nigrocincta gut. Kešnerová et al. [48] found that Bartonella apis sp. nov. was a honey bee gut symbiont. Dysgonomonas was found in low read (0.5\%). This genus has been found in other orders of insects such as Hymenoptera, Coleoptera, Lepidoptera, and Diptera, and Drosophila [48]. It has been shown as core members of gut microbiomes of non-Hawaiian Drosophila species, termites, and honeybees [49].

3.4. Bacterial Community Structure in the Gut of A. nigrocincta. Alpha diversity in terms of OTUs (lower taxa: family, genus, and species) richness and diversity was calculated using PAST3 v.3.24 (Table 1). Simpson (1-D) value 0.872 means the sample diversity is high. The index represents the probability that two individuals randomly selected from a sample will belong to different species. The dominance $(D)$ value 0.128 indicated that no taxon dominated the community altogether. The value ranges from 0 to 1 , and 0 represents infinite diversity [50]. Shannon index generally ranges between 1.5 and 3.5. Shannon index 2.488 showed that the diversity was moderate. The value is high as the number of OTUs increases and the distribution of individuals among the taxa becomes even. The diversity produced by Shannon-Wiener index $\left(\mathrm{H}^{\prime}\right)$ is equivalent to one community containing equally common species of $\mathrm{e}^{\mathrm{H}}$ which is termed as the effective number of species (ENS).
TABle 1: Alpha diversity of the OTUs in A. nigrocincta gut calculated using PAST3.

\begin{tabular}{lcc}
\hline Alpha diversity & Value & Interpretation \\
\hline Dominance D & $0.128 \pm 0.001$ & No dominance \\
Simpson D' $=1-\mathrm{D}$ & $0.872 \pm 0.001$ & High diversity \\
Shannon $\mathrm{H}^{\prime}$ & $2.488 \pm 0.008$ & Moderate diversity \\
Evenness $\mathrm{e}^{\mathrm{H} / \mathrm{S}}$ & $0.232 \pm 0.002$ & No evenness \\
Margalef (Dmg) & $4.03 \pm 0.000$ & High richness \\
Equitability J & $0.630 \pm 0.002$ & \\
\hline
\end{tabular}

This is the number of equally abundant species needed to produce the observed diversity values [51]. The $\mathrm{H}^{\prime}$ value of lower taxa of OTUs was 2.488. This has the equivalent value of diversity as a community with an effective number of species (true diversity) ( $\mathrm{e}^{2.488}$ ) of 12.04 (high diversity).

Margalef index is the simplest measurement of biodiversity [52]. The value of 4.503 indicated a high level of taxa richness. The value of evenness index 0.232 indicates that there was no evenness of the community. Evenness was also calculated using a Lorenz curve. The bacteria's distribution was uneven since the curve was farther away from perfect evenness (diagonal line) (Figure 4). The more diverse the taxa, the more uneven the abundance of each taxon [52]. The composition and structure of microbial OTUs in the gut were affected by the host social status, rather than hostage [26]. Some study showed that Shannon diversity index for foraging bee is approximately 0.69 [19], 0.9 [8], 2 [53], 3 [21], and $4[54]$ and for queen bumblebee after hibernation was 3 [55]. Shannon diversity index was higher for nurses, males, and queens [53]. The simpson index for foraging bees was 0.1 [21]. 


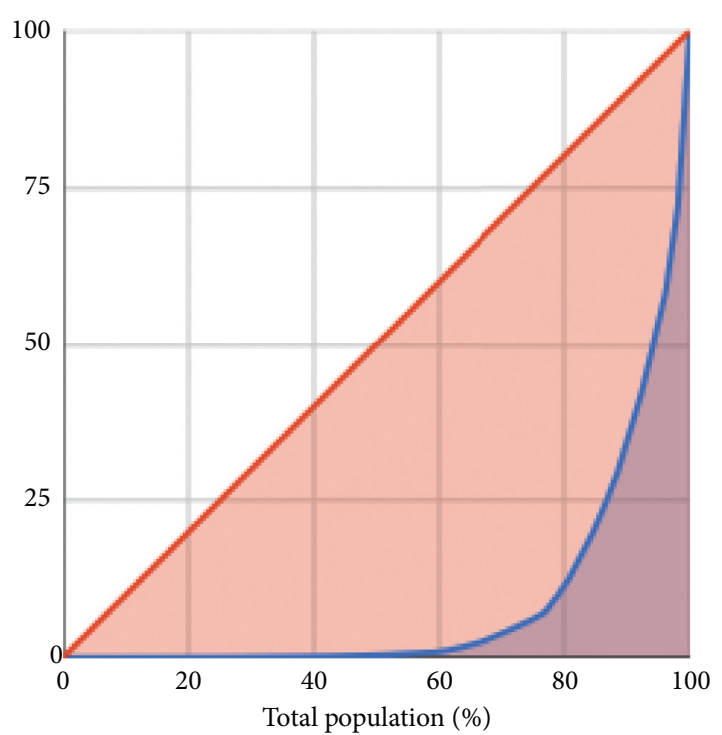

FIgURE 4: Lorenz curve of evenness of the OTUs.

TABle 2: Alpha diversity of the phyla in A. nigrocincta gut calculated using PAST3.

\begin{tabular}{lcc}
\hline Alpha diversity & Value & Interpretation \\
\hline Dominance D & $0.431 \pm 0.003$ & Moderate dominance \\
Simpson 1 - D & $0.569 \pm 0.003$ & Moderate diversity \\
Shannon H & $1.043 \pm 0.006$ & Low diversity \\
Evenness $\mathrm{e}^{\mathrm{H} / \mathrm{S}}$ & $0.405 \pm 0.002$ & Moderate evenness \\
Margalef $(\mathrm{Dmg})$ & $0.530 \pm 0.000$ & Moderate richness \\
Equitability J & $0.536 \pm 0.003$ & \\
\hline
\end{tabular}

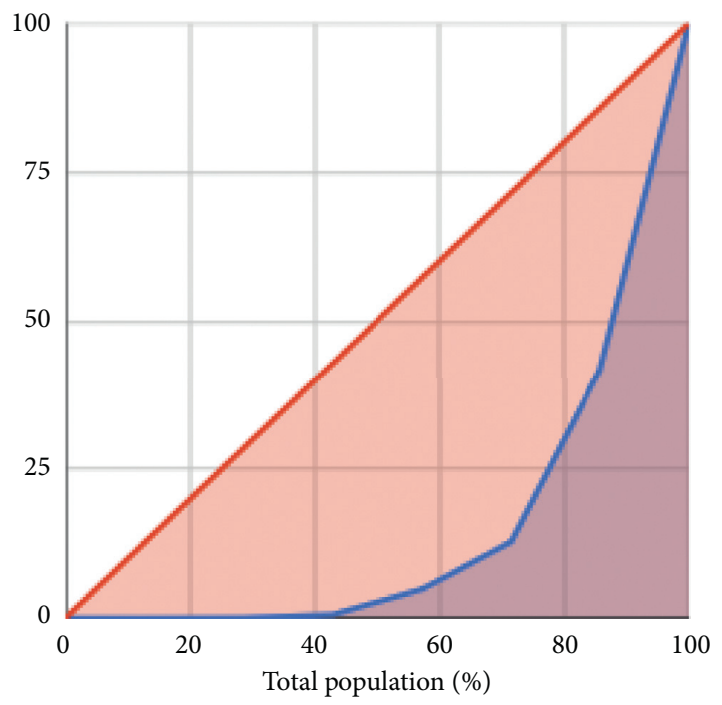

FIGURE 5: Lorenz curve of evenness of the phyla.

The evenness index for foraging bees was 0.69 [19] and 0.7 for queen bumblebee after hibernation [55].

Alpha diversity of the phyla residing in the gut of $A$. nigrocincta was calculated using PAST3 (Table 2). The dominance $(D)$ value 0.4312 indicates no phylum dominated the community completely. Simpson $(1-\mathrm{D})$ value 0.5688 means the phyla diversity was moderate. Shannon index 1.043 shows that phyla diversity was low. The $\mathrm{H}^{\prime}$ value of phyla was 1.043. This has the equivalent value with ENS 2.8 (slightly high). The value of evenness index 0.4053 indicates that there was a moderate evenness in the community. The value of Margalef index 4.503 indicates moderate phyla richness. Evenness was also calculated using a Lorenz curve (Figure 5). The distribution of the bacterial phyla was uneven as the curve is farther away from perfect evenness. It seems that the phylum diversity in the gut of A. nigrocincta as quite low. In this study, 6 phyla were found, while Yun et al. [21] found eight phyla: Firmicutes (56.65\%), Proteobacteria (42.16\%), Bacteroidetes (0.55\%), Actinobacteria (0.41\%), Cyanobacteria $(0.14 \%)$, Tenericutes $(0.04 \%)$, Fusobacteria (0.04\%), and Acidobacteria (0.006\%).

\section{Conclusions}

This present study outlines a detailed investigation of the bacterial composition and community structure in the gut of A. nigrocincta by high-throughput sequencing using V3-V4 $16 \mathrm{~S}$ rRNA regions. In conclusion, this study shows moderate OTUs and low phyla diversity of the bacteria. Proteobacteria predominated the phyla, Firmicutes, and Actinobacteria. This investigation of the bacterial microbiome of $A$. nigrocincta provides insight into the relationship between the gut bacterial community and the host. Hence, further studies will be required to elucidate more about the relationship between bacterial symbionts and the insect. Furthermore, this finding can be used as a basis for bioprospecting research.

\section{Data Availability}

The data used to support the findings of this study are available from the corresponding author upon request.

\section{Conflicts of Interest}

The authors declare that they have no conflicts of interest.

\section{Acknowledgments}

This research was partially supported by the grants from the Directorate of Research and Community Service, Ministry of Research, Technology, and Higher Education of the Republic of Indonesia, through the Higher Education Excellence Applied Research (PTUPT) (grant no. 202/UN12.13/LT/ 2019).

\section{References}

[1] J. E. Powell, V. G. Martinson, K. Urban-Mead, and N. A. Moran, "Routes of acquisition of the gut microbiota of the honey bee Apis mellifera," Applied and Environmental Microbiology, vol. 80, no. 23, pp. 7378-7387, 2014.

[2] J. C. Jones, C. Fruciano, F. Hildebrand et al., "Gut microbiota composition is associated with environmental landscape in honey bees," Ecology and Evolution, vol. 8, no. 1, pp. 441-451, 2017. 
[3] P. Engel and N. A. Moran, "The gut microbiota of insects diversity in structure and function," FEMS Microbiology Reviews, vol. 37, no. 5, pp. 699-735, 2013.

[4] P. Engel, V. G. Martinson, and N. A. Moran, "Functional diversity within the simple gut microbiota of the honey bee," Proceedings of the National Academy of Sciences, vol. 109, no. 27, pp. 11002-11007, 2012.

[5] M. Krishnan, C. Bharathiraja, J. Pandiarajan, V. A. Prasanna, J. Rajendhran, and P. Gunasekaran, "Insect gut microbiomean unexploited reserve for biotechnological application," Asian Pacific Journal of Tropical Biomedicine, vol. 4, no. 1, pp. S16-S21, 2014.

[6] V. G. Martinson, J. Moy, and N. A. Moran, "Establishment of characteristic gut bacteria during development of the honeybee worker," Applied and Environmental Microbiology, vol. 78, no. 8, pp. 2830-2840, 2012.

[7] N. A. Moran, "Genomics of the honey bee microbiome," Current Opinion in Insect Science, vol. 10, pp. 22-28, 2015.

[8] J. C. Jones, C. Fruciano, J. Marchant et al., "The gut microbiome is associated with behavioural task in honey bees," Insectes Sociaux, vol. 65, no. 3, pp. 419-429, 2018.

[9] N. A. Moran, A. K. Hansen, J. E. Powell, and Z. L. Sabree, "Distinctive gut microbiota of honey bees assessed using deep sampling from individual worker bees," PLoS One, vol. 7, no. 4, 2012.

[10] W. K. Kwong and N. A. Moran, "Gut microbial communities of social bees," Nature Reviews Microbiology, vol. 14, no. 6, pp. 374-384, 2016.

[11] K. Raymann and N. A. Moran, "The role of the gut microbiome in health and disease of adult honey bee workers," Current Opinion in Insect Science, vol. 26, pp. 97-104, 2018.

[12] T. E. Tallei, R. Koneri, and B. J. Kolondam, "Sequence analysis of the cytochrome $\mathrm{C}$ oxidase subunit I gene of Pseudagrion pilidorsum (Odonata: coenagrionidae)," Makara Journal of Science, vol. 21, no. 1, pp. 43-52, 2017.

[13] O. Folmer, M. Black, W. Hoeh, R. Lutz, and R. Vrijenhoek, "DNA primers for amplification of mitochondrial cytochrome $\mathrm{c}$ oxidase subunit I from diverse metazoan invertebrate," Mol Mar Biol Biotechnol, vol. 3, no. 5, pp. 294-299, 1994.

[14] T. E. Tallei and B. J. Kolondam, "DNA barcoding of Sangihe nutmeg (myristica fragrans) using mat $\mathrm{K}$ gene," HAYATI Journal of Biosciences, vol. 22, no. 1, pp. 41-47, 2015.

[15] Fatimawali, B. J. Kepel, M. A. Gani, and T. E. Tallei, "Comparison of bacterial community structure and diversity in traditional gold mining waste disposal site and rice field by using a metabarcoding approach," International Journal of Microbiology, vol. 2020, pp. 1-8, 2020.

[16] T. E. Tallei, P. J. J. Fatimawali, and J. J. Pelealu, "The data on metagenomic profile of bacterial diversity changes in the different concentration of fermented romaine lettuce brine," Data in Brief, vol. 25, 2019.

[17] Ø Hammer, D. A. T. Harper, and P. D. Ryan, "PAST: paleontological statistics software package for education and data analysis," Palaeontologia Electronica, vol. 4, no. 1, 2001.

[18] S. Hadisoesilo, "The diversity of indigenous honey bee species of Indonesia," Biodiversitas, Journal of Biological Diversity, vol. 2, no. 1, pp. 123-128, 2001.

[19] M. A. Horton, R. Oliver, and I. L. Newton, "No apparent correlation between honey bee forager gut microbiota and honey production," PeerJournal, vol. 3, p. e1329, 2015.

[20] A. Al-Ghamdi, K. Ali Khan, M. Javed Ansari, S. B. Almasaudi, S. Al-Kahtani, and S. Al-Kahtanic, "Effect of gut bacterial isolates from Apis mellifera jemenitica on Paenibacillus larvae infected bee larvae," Saudi Journal of Biological Sciences, vol. 25, no. 2, pp. 383-387, 2018.

[21] J.-H. Yun, M.-J. Jung, P. S. Kim, and J.-W. Bae, "Social status shapes the bacterial and fungal gut communities of the honey bee," Scientific Reports, vol. 8, no. 1, p. 2019, 2018.

[22] S. Romero, A. Nastasa, A. Chapman, W. K. Kwong, and L. J. Foster, "The honey bee gut microbiota: strategies for study and characterization," Insect Molecular Biology, vol. 28, no. 4, pp. 455-472, 2019.

[23] F. J. Lee, D. B. Rusch, F. J. Stewart, H. R. Mattila, and I. L. G. Newton, "Saccharide breakdown and fermentation by the honey bee gut microbiome," Environmental Microbiology, vol. 17, no. 3, pp. 796-815, 2014.

[24] M. T. Linjordet, A Comparative Analysis of Lactic Acid Bacteria Isolated from Honeybee Gut and Flowers, with Focus on Phylogeny and Plasmid, Norwegian University of Life Sciences, Norwegia, MA, USA, 2016.

[25] P. Svec, L. A. Devriese, I. Sedlácek et al., "Enterococcus haemoperoxidus sp. nov. and Enterococcus moraviensis sp. nov., isolated from water," International Journal of Systematic and Evolutionary Microbiology, vol. 51, no. 4, pp. 1567-1574, 2001.

[26] J.-H. Yun, S. W. Roh, T. W. Whon et al., "Insect gut bacterial diversity determined by environmental habitat, diet, developmental stage, and phylogeny of host," Applied and Environmental Microbiology, vol. 80, no. 17, pp. 5254-5264, 2014.

[27] J. E. Powell, D. Eiri, N. A. Moran, and J. Rangel, "Modulation of the honey bee queen microbiota: effects of early social contact," PloS one, vol. 13, no. 7, 2018.

[28] W. K. Kwong, P. Engel, H. Koch, and N. A. Moran, "Genomics and host specialization of honey bee and bumble bee gut symbionts," Proceedings of the National Academy of Sciences, vol. 111, no. 31, pp. 11509-11514, 2014.

[29] A. Gibello, F. Galán-Sánchez, M. M. Blanco, M. RodríguezIglesias, L. Domínguez, and J. F. Fernández-Garayzábal, “The zoonotic potential of Lactococcus garvieae: an overview on microbiology, epidemiology, virulence factors and relationship with its presence in foods," Research in Veterinary Science, vol. 109, pp. 59-70, 2016.

[30] T. T. Choksi and F. Dadani, "Reviewing the emergence ofLactococcus garvieae: a case of catheter associated urinary tract infection caused byLactococcus garvieaeandEscherichia coliCoinfection," Case Reports in Infectious Diseases, vol. 2017, pp. 1-4, 2017.

[31] T. Zhang, J. Xie, M. Zhang, N. Fu, and Y. Zhang, "Effect of a potential probioticsLactococcus garvieaeB301 on the growth performance, immune parameters and caecum microflora of broiler chickens," Journal of Animal Physiology and Animal Nutrition, vol. 100, no. 3, pp. 413-421, 2016.

[32] E. N. Abdelfatah and H. H. H. Mahboub, "Studies on the effect of Lactococcus garvieae of dairy origin on both cheese and nile tilapia (O. niloticus)," International Journal of Veterinary Science and Medicine, vol. 6, no. 2, pp. 201-207, 2018.

[33] G. Elbaradei, A. Delacroixbuchet, and J. Ogier, "Bacterial biodiversity of traditional Zabady fermented milk," International Journal of Food Microbiology, vol. 121, no. 3, pp. 295301, 2008.

[34] S. Lamei, Y. O. O. Hu, T. C. Olofsson, A. F. Andersson, E. Forsgren, and A. Vásquez, "Improvement of identification methods for honeybee specific Lactic Acid Bacteria; future approaches," PLoS One, vol. 12, no. 3, 2017.

[35] A. Vásquez, E. Forsgren, I. Fries et al., "Symbionts as major modulators of insect health: lactic acid bacteria and honeybees," PLoS One, vol. 7, no. 3, 2012. 
[36] E. Forsgren, T. C. Olofsson, A. Vásquez, and I. Fries, "Novel lactic acid bacteria inhibitingPaenibacillus larvaein honey bee larvae," Apidologie, vol. 41, no. 1, pp. 99-108, 2010.

[37] T. C. Olofsson, È. Butler, P. Markowicz, C. Lindholm, L. Larsson, and A. Vásquez, "Lactic acid bacterial symbionts in honeybees - an unknown key to honey's antimicrobial and therapeutic activities," International Wound Journal, vol. 13, no. 5, pp. 668-679, 2016.

[38] S. K. Huang, K. T. Ye, W. F. Huang et al., "Influence of feeding type and Nosema ceranae infection on the gut microbiota of Apis cerana workers," mSystems, vol. 3, no. 6, pp. e00177-18, 2018.

[39] S. Lahtinen, A. C. Ouwehand, S. Salminen, and A. Wright, Lactic Acid Bacteria-Microbiological and Functional Aspects, CRC Press: Taylor \& Francis Group, New York, NY, USA, 4th edition, 2012.

[40] M. P. Mokoena, "Lactic acid bacteria and their bacteriocins: classification, biosynthesis and applications against uropathogens: a mini-review," Molecules, vol. 22, no. 8, p. 1255, 2017.

[41] H. Koch and P. Schmid-Hempel, "Socially transmitted gut microbiota protect bumble bees against an intestinal parasite," Proceedings of the National Academy of Sciences, vol. 108, no. 48, pp. 19288-19292, 2011.

[42] M. C. Audisio, M. J. Torres, D. C. Sabaté, C. Ibarguren, and M. C. Apella, "Properties of different lactic acid bacteria isolated from Apis mellifera L. bee-gut," Microbiology Research, vol. 166, no. 1, pp. 1-13, 2011.

[43] T. Disayathanoowat, M. Yoshiyama, K. Kimura, and P. Chantawannakul, "Isolation and characterization of bacteria from the midgut of the Asian honey bee (Apis cerana indica)," Journal of Apicultural Research, vol. 51, no. 4, pp. 312-319, 2012.

[44] G. Liu, C. M. Tang, and R. M. Exley, "Non-pathogenic Neisseria: members of an abundant, multi-habitat, diverse genus," Microbiology, vol. 161, no. 7, pp. 1297-1312, 2015.

[45] W. K. Kwong and N. A. Moran, "Cultivation and characterization of the gut symbionts of honey bees and bumble bees: description of Snodgrassella alvi gen. nov., sp. nov., a member of the family Neisseriaceae of the Betaproteobacteria , and Gilliamella apicola gen. nov., sp. nov., a member of Orbaceae fam. nov., Orbales ord. nov., a sister taxon to the order 'Enterobacteriales ' of the Gammaproteobacteria," International Journal of Systematic and Evolutionary Microbiology, vol. 63, no. 6, pp. 2008-2018, 2013.

[46] H.-S. Yong, S.-L. Song, K.-O. Chua, and P.-E. Lim, "High diversity of bacterial communities in developmental stages of Bactrocera carambolae (Insecta: Tephritidae) revealed by Illumina MiSeq sequencing of $16 \mathrm{~S}$ rRNA gene," Current Microbiology, vol. 74, no. 9, pp. 1076-1082, 2017.

[47] L. Kešnerová, R. Moritz, and P. Engel, "Bartonella apis sp. nov., a honey bee gut symbiont of the class Alphaproteobacteria," Current Microbiology, vol. 66, no. 1, pp. 414-421, 2016.

[48] V. G. Martinson, J. Carpinteyro-Ponce, N. A. Moran, and T. A. Markow, "A distinctive and host-restricted gut microbiota in populations of a cactophilic Drosophila species," Applied and Environmental Microbiology, vol. 83, no. 23, pp. e01551-17, 2017.

[49] K. Poff, H. Stever, J. Reil et al., "The native Hawaiian insect microbiome initiative: a critical perspective for Hawaiian insect evolution," Insects, vol. 8, no. 4, p. 130, 2017.

[50] L. N. Lemos, R. R. Fulthorpe, E. W. Triplett, and L. F. W. Roesch, "Rethinking microbial diversity analysis in the high throughput sequencing era," Journal of Microbiological Methods, vol. 86, no. 1, pp. 42-51, 2011.

[51] L. Jost, "Entropy and diversity," Oikos, vol. 113, no. 2, pp. 363-375, 2006.

[52] T. E. Tallei and T. V. R. Saroyo, "Wild birds diversity in mount tumpa forest park, North Sulawesi, Indonesia," Bioscience Research, vol. 15, no. 1, pp. 443-452, 2018.

[53] K. M. Kapheim, V. D. Rao, C. J. Yeoman et al., "Caste-specific differences in hindgut microbial communities of honey bees (Apis mellifera)," PLoS One, vol. 10, no. 4, 2015.

[54] K. Raymann, Z. Shaffer, and N. A. Moran, "Antibiotic exposure perturbs the gut microbiota and elevates mortality in honeybees," PLoS Biology, vol. 15, no. 3, 2017.

[55] L. Bosmans, M. Pozo, C. Verreth et al., "Hibernation leads to altered gut communities in bumblebee queens (Bombus terrestris)," Insects, vol. 9, no. 4, p. 188, 2018. 